emissions globally may have increased threefold, so ammonium levels in the ice sheet should have followed a similar trend. Instead, the ice-core data seem to reveal a shallow decrease in recent decades. Atmospheric chemists have an answer for this: the true trend in emissions may have been masked by an increase in anthropogenic sulphate aerosol, which could scavenge the ammonium whilst it was being transported to Greenland. Indeed, new data from both the GISP2 and GRIP cores show that prominent increases in non-sea-salt chloride during the past century may also be linked to the recent acidification of the atmosphere, as sulphuric acid reacts with sodium chloride. Such interactions illustrate the dangers of simplistic interpretations of some of the more active constituents in ice cores.

One of the most significant results discussed at the meeting was the revelation that methane levels measured in the Summit core closely paralleled the inferred temperature changes during periods of extremely unstable climate towards the end of the last glacial period (from 40,000 to 20,000 years ago), as well as during the 'Younger Dryas' cold period and during the 'Little Ice Age' of about AD 1550-1800 (B. Stauffer, Bern University). This is the strongest evidence yet for a positive climate forcing by one of the main greenhouse gases (molecule for molecule, methane is 21 times as powerful a greenhouse gas as carbon dioxide).

Concentrations of methane in the atmosphere are limited by photochemically derived $\mathrm{OH}$ radicals, which are the principal oxidizing agent in the troposphere and limit the lifetime of many pollutants in the modern atmosphere. Recent photochemical model calculations (A. Thompson, NASA/Goddard Laboratory) predict methane mixing ratios that are broadly confirmed by the ice-core data for both the Last Glacial Maximum and for the pre-industrial Holocene, and suggest that the changes are largely driven by changes in emission rates.

Most of the other species of interest have very much shorter residence times in the atmosphere and so show much greater geographical variations. The most obvious difference between the Earth's polar regions is that the Arctic regions are landlocked, surrounded by the great industrialized nations, whereas Antarctica is surrounded by the Southern Ocean. This marked asymmetry can help to separate the contributions from different sources, especially for the tropospheric aerosol components which have a particularly short residence time in the atmosphere. One consequence is that it is still possible to study in recent snows the natural biogeochemical cycles of nitrogen and sulphur in Antarctica, where the effects of pollution are virtually undetect- able; in the Arctic, these cycles have been strongly perturbed by pollution.

Sulphate aerosols are thought to influence climate feedback both by scattering solar radiation directly and by altering the reflectivity of clouds. There may also be feedback between climate and the natural sulphur cycle. Given the marine setting, it is not surprising that sulphur in Antarctic ice is normally dominated by compounds derived from marine algae. One of these, methanesulphonic acid, varies strongly on both decadal and glacial to interglacial timescales, suggesting important, largescale changes in marine biological activity. Although this may well be so, recent work has shown that wind speed (patently a climatic factor) strongly affects the rate of exchange of the marine sulphur compounds into the atmosphere (E. Saltzman, Miami University).

Moreover, the production of dimethyl sulphide, the precursor of methanesulphonic acid, depends on the distribution of planktonic species. The variations observed in the ice-core record are thus the net result of several complex and interconnected factors. Patterns of behaviour in the Arctic and the Antarctic seem to be strikingly different during the coldest parts of the last ice age. Whereas methanesulphonic acid shows large increases at several Antarctic sites, new data from Renland, Greenland, a low-altitude site, show it to decrease (Saltzman). Possibly this reflects changes in a local source for the northern data. Research on these sulphur species should have much to add to our knowledge of changes in ocean conditions, a further crucial factor in climate change.

The behaviour of sulphur is complex because so many varied sources are involved, including the overwhelming anthropogenic contribution in the Northern Hemisphere during the past few decades. In the Arctic, progress is being made towards establishing the links between climate and aerosol chemistry, including the sulphur species (L. Barrie, Atmospheric Environment Service, Ontario). This research is done at groundbased stations such as Alert; if it could be extended to areas around ice-drilling sites in Antarctica and Greenland, where it could be combined with investigations of how atmospheric impurities are deposited in the local snowfall, we should obtain a firmer basis for translating ice-core chemistry into atmospheric chemistry. Ice cores could then offer a relatively low-cost means of extending direct atmospheric sampling to the distant past, where no satellite probe can reach, providing urgently needed information for global models of atmospheric chemistry.

David A. Peel is at the British Antarctic Survey, NERC, High Cross, Madingley Road, Cambridge CB3 OET, UK.

\section{Waxing Moon}

A RECENT Russian satellite reflected back to Earth a feeble artificial moonlight. Daedalus now plans to improve the real thing. He points out that the Moon reflects only about 5 per cent of sunlight - little better than soot. If, like magnesium oxide, it reflected 95 per cent of sunlight, moonlight would be twenty times as bright.

At first Daedalus had visions of some desperate Apollo project, with rocket loads of magnesium oxide being ferried to the Moon, and astronauts with bulldozers spreading it about. But he now has a much neater idea. A rocket motor burning magnesium in oxygen could eject an exhaust plume of magnesium oxide at more than $5 \mathrm{~km} \mathrm{~s}^{-1}$. Fired in the vacuum of space, this plume would travel quite ballistically. It could be aimed at the Moon from a great distance, and would impact it as evenly distributed dust. Magnesium oxide smoke is so finely divided that a mere ten million tonnes of it could cover the whole visible face of the Moon with a dazzlingly white reflecting layer.

The obvious technology for this job is the high-velocity gun developed as a space launcher for the Canadian 'Harp' project. It should be set up in the Himalayas, perhaps on the already overcrowded Mount Everest, to minimize air-resistance to the projectile. Once in space, this would be accelerated towards the Moon by a booster rocket. At its closest approach, it would ignite a motor burning magnesium powder in lithium perchlorate. This mixture burns to magnesium oxide and lithium chloride (another very white solid). An orientation package would aim the fast-moving plume so as to impact the lunar surface. Guns are so cheap compared to space rockets that a heavy lunar barrage could be sustained for years, until the whole surface of the Moon was evenly dusted with magnesium oxide.

Life on Earth would be transformed. Dazzlingly bright moonlight would save billions on street lighting everywhere. Lovers would blink in its unromantic glare, while nocturnal criminals and conspirators vainly sought concealment from the lunar searchlight. Siberia and the Canadian north, released from their dark winters, would flourish as never before. Flowering plants might be confused by the seemingly endless summer daylight; but the monthly newMoon period should give them an adequate clue to the true season. The cost of the project would be recovered many times over. But to fund its early days, the first white strokes on the dark lunar surface should perhaps take the form of advertising slogans. David Jones 